\title{
Improved Analysis of DVR Performance for Voltage Sag Mitigation
}

\author{
Hannah Naqiah Abdul Razak, Dalila Mat Said" and Nasarudin Ahmad \\ School of Electrical Engineering, Faculty of Engineering, UniversitiTeknologi Malaysia, \\ 81310 UTM Skudai, Johor, Malaysia.
}

*Corresponding author: dalila@utm.my

\begin{abstract}
Dynamic Voltage Restorer (DVR) provides the most reliable solution to the voltage quality problem in power distribution system from the effectiveness of DVR performance for voltage sag mitigation. As a custom power device, DVR offers the best solution to three phase power system in order to improve the power quality issue as the magnitude and phase of the voltage is added during the sags occurrence to restore the load condition to compensate the voltage sags. The suitable controller, Proportional-Integral (PI) Controller is used along with the Pulse Width Modulation (PWM)-based control scheme to calculate the exact error and generate the missing voltage to be injected to the three-phase power system through injection transformers. Simulation results of various fault types using MATLAB/SIMULINK are shown in this paper to demonstrate the successful compensation of voltage sags by mitigation technique using Dynamic Voltage Restorer in three-phase power distribution.
\end{abstract}

Keywords: Voltage Sag Mitigation; Dynamic Voltage Restorer (DVR); Proportional Integral (PI) Controller; Pulse Width Modulation (PWM)

(C) 2018 Penerbit UTM Press. All rights reserved

Article History: received 5 August 2018; accepted 13 December 2018; published 26 December 2018

\section{INTRODUCTION}

Power quality is vital and has become significant in this modern environment since regular electrical consumption involved in industrial and residential area. Voltage and current should be maintained at optimum value by reducing the disruption or disturbance in order to conserve the power quality distributed to the end users. There are immense types of power quality issues which are voltage sags, swells, harmonics, under voltage, over voltage that have caused interruptions and damaged to the sensitive load equipment. From the statistical analysis, it shows voltage sags is one of the most severe disturbances among the power quality issues considering it may affect the manufacturing process involving semiconductor industries or damaging sensitive load.

Therefore, the perfect approach to mitigate voltage sags is to apply DVR to minimize the interruptions at load condition by injecting voltage in series with the power distribution system during the occurrence of sags. DVR is appraised as an effective and efficient custom power device in mitigate this power quality problem due to its capabilities compared to other Custom Power Device, CPD. Basic configurations that covered in DVR are linear transformers, Voltage Source Inverter (VSI), storage device, DC charging circuit and control circuit.

\section{POWER QUALITY}

One of the most prominent issues or top contributors to the power quality problem is voltage sags [1]. Voltage sags is one of the most extreme disturbances due to its effect to the utility company and consumers as it can cause malfunction to sensitive electronic equipment [2]. Voltage sags can be mitigate by many CPD such as DVR, Uninterruptable Power Supplies (UPS), Static Voltage Compensators (SVC), Distributed Static Compensators (DSTATCOM), and Super-Magnetic Energy Storage (SMES) [2]. However among other CPD, DVR is the most preferred and effective solution since it has numerous advantages such as fast dynamic response, lower in cost, higher energy capacity, smaller size and the most simplest device [3].

The principle of DVR is to insert missing voltage during sags disturbances in series with transmission line between the supply and load at the common coupling point (PCC) to compensate voltage sags at load side [4]. There have been many researches of DVR proposed in a decade yet there are several factors which can affect performance of DVR such as energy storage capacity and transformer rating [5]. Therefore in order to enhance the performance of DVR in mitigating voltage sags, the energy storage capacity need to be increased which is the least it can be is $110 \mathrm{~V}$ to compensate voltage drop above $0.9 \mathrm{pu}$ while the injection transformer rating need higher $\mathrm{kVA}$ due to less total harmonic distortion (THD) generated for the enhancement of output voltage [5]. Unfortunately, transformer with higher rating is more expensive [5].

There are many controllers have been proposed which act as the control circuit of DVR and its main function is to control the operation of DVR by detecting voltage sags and calculate the desired value of the compensated voltage 
to be injected by DVR [5]. The most applicable controller for DVR is PI controller with PWM-based control scheme [6]. The combination of this method has many advantages which result in minimize DVR power rating, increase the accuracy of the sags and phase angle jump compensation [6]. PI controller will calculate the difference values of measured and referenced value so it can reduce the error through adjustment which will be fed to PWM.

The voltage has to be transformed to the original waveforms it will be the input for the PWM to produce triggering signal to VSI to convert the voltage from DC to $\mathrm{AC}$ to be injected to the injection transformer [6]. VSI is based on PWM method since CPD only apply low power and it is more simple and good in response due to its flexibility compared to Fundamental Frequency Switching (FFS) [7]. Plus, the efficiency of the VSI can be improved by high switching frequencies offered by PWM without causing significant switching losses [7]. Closed-loop control applied by the PI controller is applicable due to its high precision than open loop control since it comprises of voltage damping due to the existence of filter which can caused voltage oscillation or severe effect to the sensitive load [8]. It also cause the current surge into the DC capacitor, eventually leave the DC capacitor overcharged and avert the load voltage to be compensated to desired value due to the existence of the filter [8].

Among all researches, it stated that out of three types of switching devices which are Metal Oxide Semiconductor Field Effect Transistor (MOSFET), Gate Turn-Off Thyristors (GTO) and Insulated Gate Bipolar Transistor (IGBT), IGBT is considered for Voltage Source Inverter (VSI) due to its superior characteristic for DVR to compensate voltage sags compared to others due to their limitations such as MOSFET caused voltage limit increased when on-resistance increased while GTO is only suitable for high voltage application and it is a latching device which needed to be turn off by negative pulse plus it does not able to meet the requirements of DVR [9]. IGBT is the switching device that is used in VSI for the DVR operation because a IGBT connect in freewheeling diode between each other therefore more flexible as it reduces switching losses [2].

Therefore, with the motivation of having less transformer rating due to appropriate price, applicable controller with high accuracy and precision of sag depth and phase jumps in order to regulate voltage sags in fast dynamic response with better efficiency without switching losses, DVR with PI controller with PWM technique in dq0 transformation is proposed. In conclusion, DVR is considered as effective method to mitigate voltage sags to improve the power quality in quick response and high reliability due to its capability of all appropriate components chosen in shielding sensitive loads from the short duration of sags [10].

\section{METHODOLOGY}

This research begins with the accumulation of fundamental knowledge of voltage sags in power quality enhancement with previous DVR techniques. As shown in Figure 1 below, after three-phase supply system had been created with fault or voltage sags, the simulation is then followed by the development of the control circuit algorithm which is PI controller PWM-based control scheme. The missing voltage generated will be filtered by the filter unit and injected to the three-phase supply system through the injection transformer to regulate the load voltage. The proposed algorithm will be validated on the Simulink MATLAB to prove the DVR performance in dealing with voltage sags as to enhance the power quality.

\subsection{Modelling of Three-Phase Power System at Distribution Side}

Three phase power system at distribution is developed in the first place of demonstration and connected to RLC load. The voltage at the grid is labelled Vabc and the voltage at load is labelled V-L then both voltages were measured by scopes as shown in Figure 1. Since voltage sags occur at distribution and transmission line, the fault will be generated to the power distribution system to see the load at the voltage side. Therefore, three phase power distribution system is simulated in the MATLAB/Simulink to show the real performance of load voltage without fault or voltage sags.

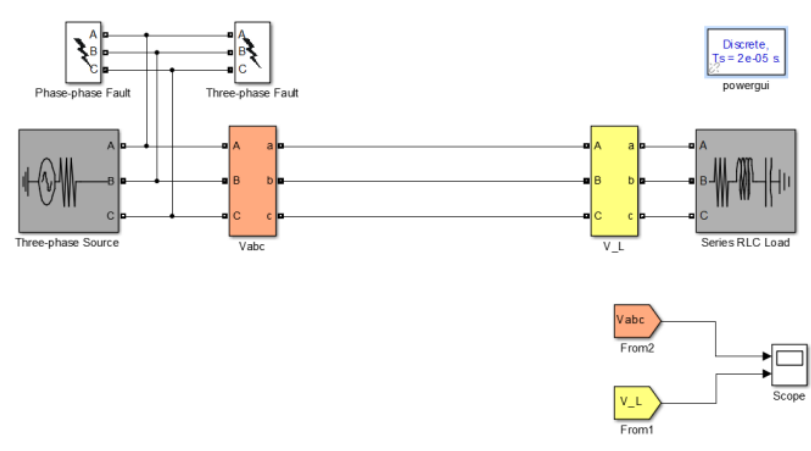

Figure 1. Simulink Blocks of Three Phase Power System Before Amplitude Variation

\subsection{Generating Voltage Sags from Three-Phase and Phase-Phase Faults Blocks}

At industrial load, voltage sags can occur at the utility system or normally affected by starting of large motors or even fault in the facilities. In this case, there are two types of fault generated as shown in Figure 2 which is phase to phase fault and three phase fault to see the effect of these faults to the load voltage performance. The times for these faults were set to $0.03 \mathrm{~s}$ to $0.07 \mathrm{~s}$ with $0.1 \Omega$ On Resistance, $\mathrm{R}_{\mathrm{on}}$ and from $0.12 \mathrm{~s}$ to $0.16 \mathrm{~s}$ with $0.07 \Omega \mathrm{R}_{\mathrm{on}}$.

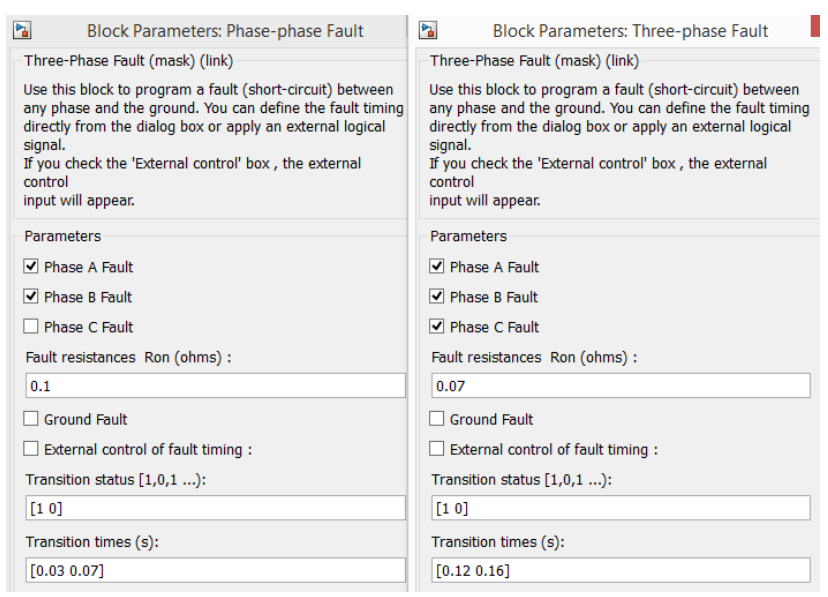

Figure 2. Phase-Phase and Three-Phase Fault Block Parameters 


\subsection{Operation of DVR}

DVR is installed in power distribution system between the supply and load feeder as can be seen in Figure 3. The main role of DVR is to inject the missing voltage in series with transmission line to control the voltage at the load side. It consists of control system which is PI Controller to control the operation of DVR, energy storage to provide DC supply during the voltage compensation, VSI to invert the DC supply to AC supply for three phase load voltage, line filter to reduce the harmonic from VSI and lastly injection transformer to inject the voltage to the load side voltage to overcome the sags in order to maintain the power quality at power distribution system.

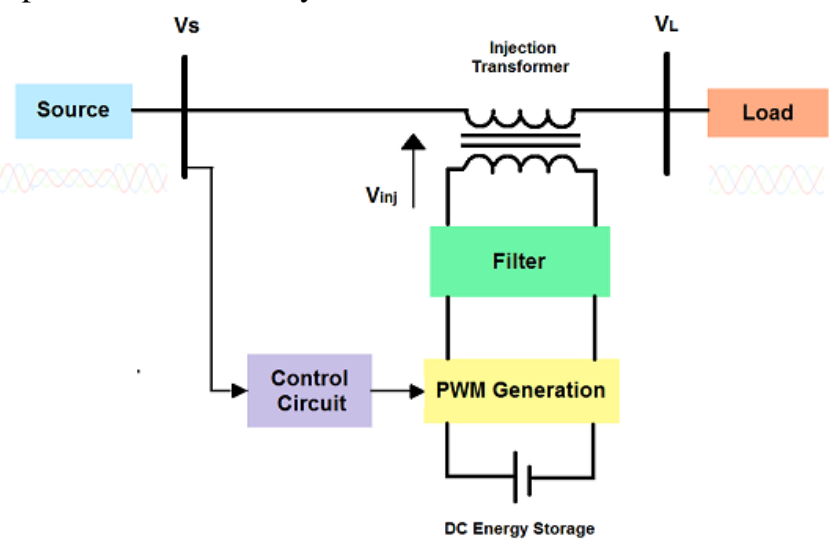

Figure 3. Block Diagram of DVR Operation

\subsection{PI Controller as Control Technique of DVR}

DVR has a control circuit which controls the operation of DVR to compensate voltage sags in power distribution system as shown in Figure 4. The control circuit which is PI controller shown in Figure 5, will monitor the load voltage by comparing it to the reference voltage. If the voltage sag occurs at the distribution side, an error signal will be generated due to the variance value between the reference and load voltage. After the error is minimized by the PI controller, the value is passed to the VSI through PWM control technique that can be seen in Figure 6. PWM generator will trigger the inverter by generating pulse in order to produce desired magnitude, phase and frequencies to be injected the missing voltage at the transmission line. Therefore, load voltage can be compensated in order to maintain the power quality in the power distribution system.

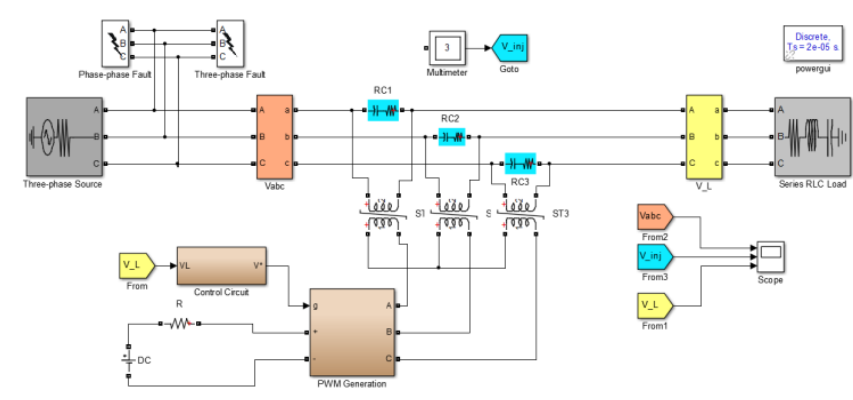

Figure 4. Three-Phase Power Distribution System with DVR

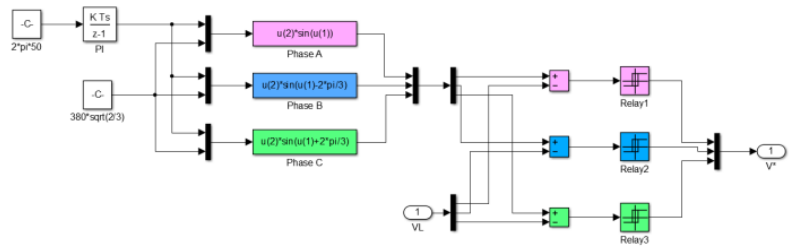

Figure 5. DVR Control Unit using PI Controller

The control unit of PI controller will generate a threephase sinusoidal waveform to be compared with uncompensated load voltage as shown in Figure 5. It is first generated from Discrete Fourier block with Gain=1 and multiplied with the same amplitude of grid voltage. The equation to generate the phase $\mathrm{a}, \mathrm{b}$ and $\mathrm{c}$ are;

$$
\begin{aligned}
& \mathrm{V}_{\mathrm{a}}=\mathrm{V}_{\mathrm{p}} \sin (\theta) \\
& \mathrm{V}_{\mathrm{b}}=\mathrm{V}_{\mathrm{p}} \sin \left(\theta-\frac{2}{3} \pi\right) \\
& \mathrm{V}_{\mathrm{c}}=\mathrm{V}_{\mathrm{p}} \sin \left(\theta+\frac{2}{3} \pi\right)
\end{aligned}
$$

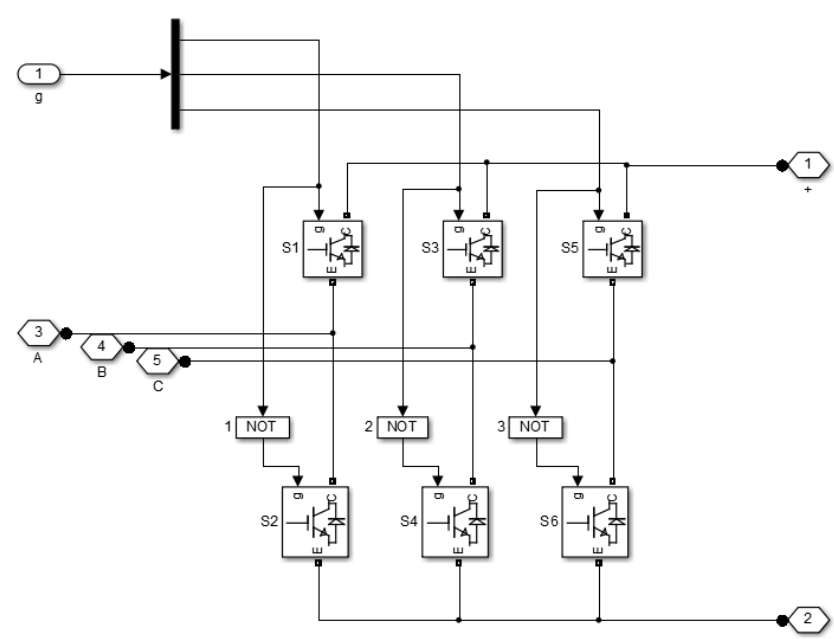

Figure 6. Voltage Source Inverter by PWM Control Technique

PWM based control scheme is applied as the voltage source inverter to invert the DC Energy Storage to threephase sinusoidal AC voltage during voltage sag compensation. PWM inverter will be triggered by the PWM generator to produce the required firing sequence with IGBT as the switching device and its output will be ready to be injected at the load terminal.

\section{RESULTS AND ANALYSIS}

Figure 7 shows the normal voltage at the grid and load side before voltage sags is applied to the power distribution system. Three phase voltage is free from voltage sags or voltage reduction which is different from Figure 8 that experienced phase to phase fault from $0.03 \mathrm{~s}$ to $0.07 \mathrm{~s}$ and three phase fault from $0.13 \mathrm{~s}$ to $0.17 \mathrm{~s}$ due to the generation of voltage sag with $R_{\text {on }}$ of $0.1 \Omega$ and $0.07 \Omega$. It can be seen from Figure 8 that voltage reduction value will be smaller when the $\mathrm{R}_{\mathrm{on}}$ is small. 
Figure 10 and 11 shown below are the simulation results after the implementation of DVR to the power distribution system. Figure 10 is the simulation result during standby mode of DVR operation when $\mathrm{V}_{\mathrm{DVR}}<0$. Since there is no voltage sag generated from the threephase programmable voltage source, DVR system should have no effect to the main system. Therefore it can be seen from Figure 10 which shows load voltage remain the same as grid voltage and not affected by DVR since no injection voltage generated during the standby mode.

Figure 11 is the simulation result during injection mode of DVR operation when $V_{D V R}>0$. As the voltage sags were created in two transition times which are from $0.03 \mathrm{~s}$ to $0.07 \mathrm{~s}$ and from $0.13 \mathrm{~s}$ to $0.17 \mathrm{~s}$, it can be seen from the figure below that DVR can compensate the voltage sag by injecting the right amount of voltage reduction when the sags occurred at the supply side. As the voltage reduced to $200 \mathrm{~V}$ and $100 \mathrm{~V}$, the injection voltage by DVR injection mode are $100 \mathrm{~V}$ and $200 \mathrm{~V}$ to regulate the load voltage which proved the reliability of DVR in monitoring and minimizing voltage sags at load side power distribution system.

\section{CONCLUSION}

Voltage sags is prominent more than other power quality phenomenon as the extensive use of equipment that sensitive to voltage alteration can made the industrial application more vulnerable to improper functioning, tripping and suffering from loss production and profits. Three-phase power distribution system with DVR and PI Controller modelled by MATLAB/Simulink has demonstrated the effectiveness of its performance in mitigating voltage sags. The promising control methods of DVR was successfully operated in standby mode if no voltage sags detected and operated in injection mode during the sags occurrence in the three phase power distribution system. The simulation results show clearly the ability of DVR to handle voltage sags and keep load voltage constant at distribution side.
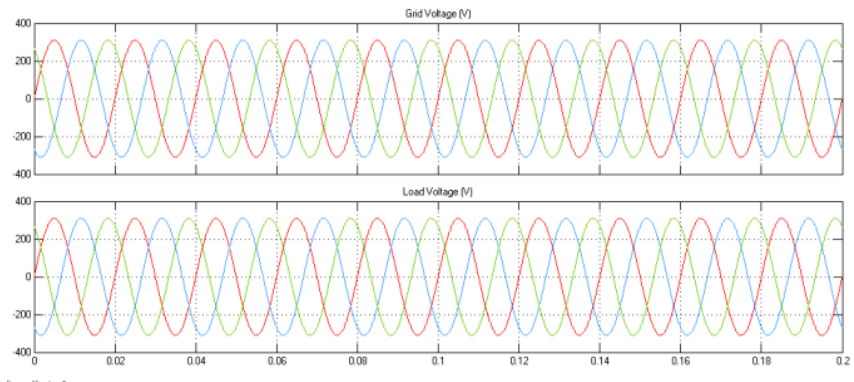

Figure 7. Grid and load voltage of power distribution system without voltage sags

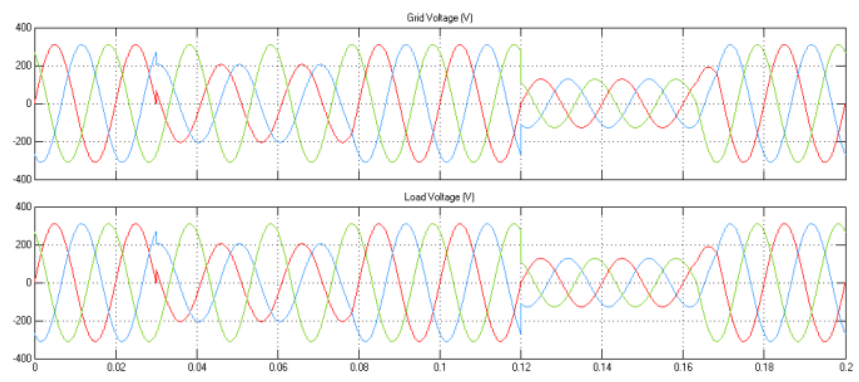

Figure 8. Grid and Load Voltage of Power Distribution System with phase to phase fault and three-phase fault

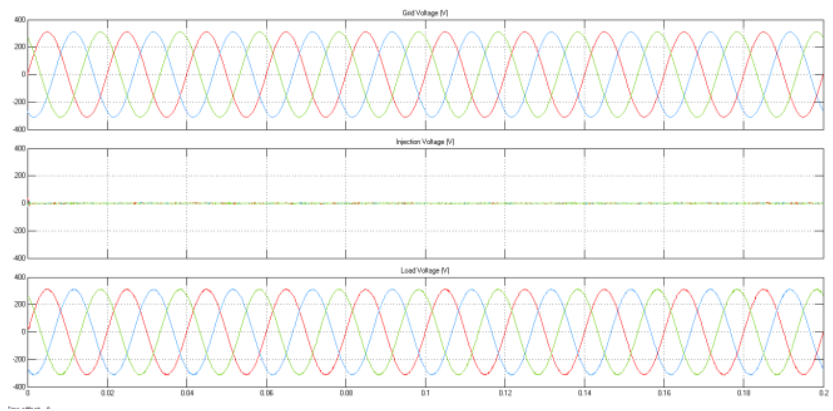

Figure 10. Grid, Injection and Load Voltage of Power Distribution System during Standby Mode

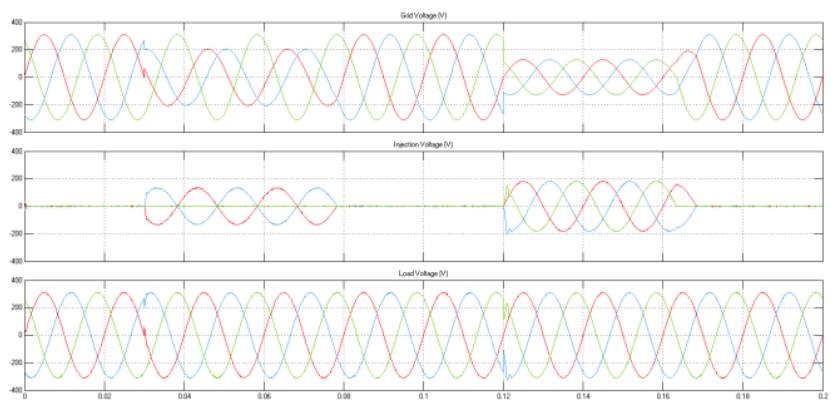

Figure 11. Grid, Injection and Load Voltage of Power Distribution System during Injection Mode

\section{REFERENCES}

[1] S. H. Chaudhary, "Mitigation of voltage sag / swell using Dynamic voltage restorer," vol. 8, no. 4, pp. 21-38, 2013.

[2] A. M. Saeed, S. H. E. Abdel Aleem, A. M. Ibrahim, M. E. Balci, and E. E. A. El-Zahab, "Power conditioning using dynamic voltage restorers under different voltage sag types," J. Adv. Res., vol. 7, no. 1, pp. 95-103, 2016.

[3] T. Devaraju, V. C. Veera Reddy, and M. Vijaya Kumar, "Performance of DVR under different voltage sag and swell conditions," J. Eng. Appl. Sci., vol. 5, no. 10, pp. 56-64, 2010.

[4] S. P. Mishra, B. Biswal, J. P. Roselyn, and D. Devaraj, "Simulation and analysis of DVR for mitigating voltage sags and swells," Procedia Eng., vol. 64, pp. 341-350, 2013.

[5] R. H. Salimin and M. S. A. Rahim, "Simulation Analysis of DVR Performance for Voltage Sag Mitigation," no. June, pp. 6-7, 2011.

[6] M. T. Ali, F. Abbas, A. Nadeem, M. Yaqoob, S. M. Malik, and M. J. Iqbal, "Effect of PI controller on efficiency of dynamic voltage restorer for compensation of voltage quality problems," 16th Int. Power Electron. Motion Control Conf. Expo. PEMC 2014, pp. 1134-1139, 2014.

[7] P. A. Raut and A. P. Q. Problems, "an Overview and Design of Dynamic Voltage Restorer To Improve Power Quality in Microgrid," no. Icesa, pp. 632-635, 2015. 
[8] W. Shi, G. Tang, and J. Li, "Control strategy of dynamic voltage restorer," Dongnan Daxue Xuebao (Ziran Kexue Ban)/Journal Southeast Univ. (Natural Sci. Ed., vol. 37, no. 1, pp. 10-13, 2007.

[9] C. Benachaiba and B. Ferdi, "Voltage Quality Improvement Using DVR," vol. XIV, no. 1, pp. 3946, 2008.
[10] R. Omar and N. a Rahim, "Design Requirements for a Dynamic Series Compensator for Voltage Sags Mitigation in Low Voltage Distribution System," Int Conf. Renew. Energies Power Qual., pp. 1-7, 2015 